\title{
ROLE OF REGULATORY AUTHORITIES ON THE WORKING OF CONTRACT RESEARCH ORGANIZATION AND PHARMACEUTICAL COMPANY'S CLINICAL TRIALS IN INDIA
}

\section{---A study of strategic alliances between pharmaceutical companies and clinical research organisations in India}

Poonam Chauhan, Monica Mendonca

K J Somaiya Institute of Management, Mumbai, India

Correspondence: poonam@somaiya.edu

\begin{abstract}
The evolution of the drug development process and testing its efficacy is a primary responsibility of pharmaceutical companies. The time cost investment involved in identifying a compound suitable to its target disease and making it available to the masses eventually led to the rise of the Contract Research Organization (CRO) in the domain of clinical research. Pharmaceutical companies outsource the research and clinical trials to CRO's. A CRO has a vital role from drug discovery to the launch and marketing of drugs. India is emerging as attractive location for global clinical trial. It has cost advantage compared to other countries and a well-developed associated services like data management, medical writing and pharmacovigilance. The Central Drug Standard Control Organization (CDSCO) is the National Regulatory Authority in India that aims to bring safe drugs and standardize clinical research.
\end{abstract}

Pharmaceutical Companies benefit by strategically working with CRO to gain speed and efficiency in drug discovery, generation and retention of clinical data integrity. The risk associated with CRO relates to delays and inferior quality of work, thereby making CRO a critical decision for Pharmaceutical Company.

\section{KEYWORDS}

Contract Research Organization (CRO), Drug Development, Clinical Trials, Regulatory Authorities, Pharmaceutical Brand Reputation.

\section{INTRODUCTION}

The pharmaceutical is one of the most regulated sectors in India as government implements various legislations to safeguard the health and welfare of people. Pharmaceutical companies select Contract Research Organisations (CRO) to carry out clinical trials and bring out a new molecule, a new treatment or innovation in medical devices. It also reduces the cost of completion of a drug research project. [1] There are risks associated with CRO regarding the conduct of trial design, confidentiality of the data, and publication of outcomes. CRO practices have 
also raised ethical concerns related to inadequate consent, safety measures or poor on-site monitoring.[2] The regulatory authorities have specific requirements from CRO's regarding the safety and efficacy of drugs and protecting public health. They have a role in ensuring the protection, and effectiveness of all pharmaceutical products distributed in their region.

The evolving regulatory framework in India poses unique challenges for compliances and has implications for the strategic alliances formed by pharmaceutical companies with CRO. [3]

\section{PURPOSE OF THE STUDY}

- To study the nature of alliances between CRO and pharmaceutical companies.

- To study the scope of regulations on clinical trials conducted by CRO for pharmaceutical companies in India

- To explore the branding implications of success or failure of clinical trials for CRO and pharmaceutica companies.

\section{INDUSTRY BACKGROUND}

\section{GLOBALIZATION OF CLINICAL TRIALS - EMERGING OPPORTUNITY FOR INDIA}

Pharmaceutical companies conducted clinical trials conventionally in technologically advanced countries like the US, UK, and Western Europe. There has been a gradual shift to emerging economies like Eastern Europe, Latin America, and Asia. The companies have to ensure that the design, oversight, and execution meet the local regulatory and ethical requirements.[4] The World Health Organisation has facilitated the registry of clinical trials at the international level for improved access of clinical trials data to all stakeholders.[5] India has the world's largest population and costs advantage, making it a favourable destination for clinical trials. [6] The rise of CRO's in India can be attributed to many factors such as minimized operational cost, possibilities of quick patient recruitment, the ease of the regulatory approval process, rapidly developing and emerging scientific research and development activities capacity. [7]

\section{PURPOSE OF CLINICAL RESEARCH ORGANIZATION}

A CRO is an outsourcing company that a sponsoring company hires as an independent contractor to lead clinical trials and other research support services on its behalf. CROs typically contract with companies in the pharmaceutical, biotechnology, or medical device industries, but their clients also include governmental institutions, foundations, and universities. [8] The strategic alliances are forged between pharmaceuticals sponsors where both share risks, and CROs are responsible for reducing the cost of the production process while retaining quality.[9]

\section{REGULATORY INFRASTRUCTURE}

The governments enforce regulations on Pharmaceutical Companies to promote safety standards and protect participants on trials. The Pharmaceutical companies expect the regulators to protect their intellectual property. Some of the prominent regulators are the European Medicine Agency (EMA). United States FDA, China's National Medical Products Administration.[10]

The chief regulatory authority in India for drugs and clinical trials is the Central Drugs Standard Control Organization (CDSCO) and the governing official of the CDSCO is the Drugs Controller General of India (DCGI), who would approve the clinical trials taking place in India.[11] The responsibilities of the DCGI would include the assessments of the clinical trial sites, sponsors, and drug manufacturing facilities with the support of the institutes such as the Indian Council of Medical Research (ICMR) and the Department of Biotechnology (DBT). These institutes have technical expertise on rare and critical diseases of national importance. Other institutes such as Drug Consultative Committee and Drug Technical Advisory Board assist the DCGI in examining the New Drug Applications. [12]

\section{METHODOLOGY}

To understand the nature of strategic alliances and regulatory influences on the relationship between CRO and Pharmaceutical companies, qualitative interviews with the following industry experts were undertaken:

1) Dr. Sudhakar Bangera: Clinical Research Professional, Trainer for Ethics Committee and Registrations of Ethics Committee.

2) Dr. Vishal Narang Ph.D, MBA: Director, Clinical Project Leadership and Operations, Cipla.India.

3) Ms.Ekta Shah; Regional Trial Manager- AP EMEA at Sanofi. India.

4) Ms. Manjari Madanan; Global Clinical Quality Specialist; IQVIA. India

5) Ms. Kartik M; Clinical Data Manager, IQVIA. India The questions were on how a pharmaceutical company in India selects a Contract Research Organization for the 
clinical trials. Does the regulatory body of the Central Drugs Standard Control Organisation influence the selection of a CRO by a pharmaceutical company? What are the benefits accrued to the pharmaceutical company by outsourcing their clinical trial to a CRO? How would the success and failure of clinical trials affect the CRO and sponsoring pharmaceutical companies?

The response of the experts interviewed is recoded, and transcriptions are prepared. The insights are summarised in the following section.

\section{DISCUSSION}

\section{DECISION MAKING CRITERIA INVOLVED IN THE SELECTION OF CONTRACT RESEARCH ORGANIZATION BY PHARMACEUTICAL COMPANIES}

Pharmaceutical companies can optimize their resources and increase innovations in drug development by alliances with CRO. Though the environment fosters outsourcing to $\mathrm{CRO}$, the relationship is fraught with challenges like CRO not being able to adhere to timelines, delays increasing project cost, lack of transparency, difficulties in design and execution of protocols.[13]

The Pharmaceutical Executive committee would initiate by creating awareness of the clinical trials requirement and activate the vendor and CRO network. The committee would then be visiting the CRO to observe their operating procedures and regulatory compliance. Alternatively, they will send out (Request for Proposal) RFP/ Proposals to several CROs. They are expected to work on the process of trial site, data-related formulations, test license, and pharmacovigilance safety reporting.

"No Law across the world says Pharma company have to hire a CRO; if they want pharma company can choose to run a clinical trial on its own with its set people or resources but the alliances are mutually beneficial" by Dr. Sudhakar Bangera.

CRO's can undertake projects on a global scale and have emerged as the centre of excellence. One successful alliance has been between Covance and SanofiAventis.[14]

A decision analysis tool can be used to identify and evaluate the competency of the contract research organization using multicriteria decision modelling.[15] The
Key Performance Indicators (KPI) metrics are also used for services they offer in the specified therapeutics domain, clinical data management, pharmacovigilance and operations.

The government of India has brought amendments in schedule $Y$ of the Drugs and Cosmetics Act (1940) to provide guidelines for the ethical conduct of clinical trials in the country. Central Drugs Standard Control Organization (CDSCO) under the Director-General of Health Services, Ministry of Health and Family Affairs is the National Regulatory Authority NRA) of India.

CDSCO has audited and ensured the ethics committee providing approval to all the clinical trials that are to take place on Indian soil are registered under its purview from the year 2013. [16]

While Regulatory Authorities are not primarily involved in CRO appointments, they consider CRO as an extension of the pharmaceutical company for any ongoing clinical trial and subject them to regulatory audits. The compensation for any trial-related death or injury is in the purview of the ethical committee. The trial sites approach the CDSCO approved ethics committee in their region to review and approve the essential clinical trial documents.[17]

"Working with a CRO with regulatory affairs/ submissions expertise is an assurance of good processes in place" by Ms. Ekta Shah.

The complex regulatory environment often requires a long time to get clearance for projects causing Phase lag, and delays in customs clearance of medical devices hamper the trial process. [18]

\section{SUCCESS OR FAILURE OF CLINICAL TRIALS IMPACTING CRO AND PHARMACEUTICAL CORPORATE BRAND REPUTATION}

The rate of Failure of Phase II and Phase III drug trials is very high globally. There reasons for failure could be lack of design protocols, inability to meet the required efficacy or the adverse effect, or the commercial non-viability. Certain therapeutic specialties like oncology and Cardiovascular have a higher failure rate, and specific recombinant proteins have a higher failure rate than monoclonal antibodies.[19].

"The CRO's track record definitely has an impact on its Brand Equity" by Dr. Vishal Narang. 
CRO have their own technologies, infrastructure, and tools to improvise treatment outcomes. For Example, the IQVIA world-renowned Contract Research Organization has used a cloud-based application (IQVIA Virtual Trial Solution) to manage virtual. The outcome of the clinical trial would impact the brand value of both CRO and pharmaceutical. More specifically both Indian CROs and globally renowned CROs will have to ramp up their clinical operations in terms of site monitoring, clinical data management, regulatory compliance.[20]

\section{FUTURE SCOPE OF THE STUDY}

The future studies can address the challenges of strategic alliances between pharmaceutical companies and contract research organizations. The pharmaceutical industry is facing intense pressure to bring out the new drugs to the market as blockbuster patents expires and research and development cost increases. Presently sponsor pharmaceutical company is the dominant player in the alliance between sponsor pharma \& CROs and it would bear complete responsibility for success or failure of the new drug molecule or new treatment and not the CROs. There is need to investigate the alignment based on value and risk sharing and regulatory compliance between the CRO's and the pharmaceutical companies.

\section{MANAGERIAL IMPLICATIONS AND CONCLUSION}

The Pharma industry spends many resources in drug discovery, but it does not translate into an increase in new therapeutics. The outsourcing to CRO helps in optimally allocating the resources. The alliance between a sponsor and CRO has both benefits and risk-associated partnership. The prevalence of different languages spoken across the country compounds the problem of informed consent for clinical trials. There is a greater responsibility on CROs to protect the integrity of the vulnerable population. [21] India has a large generics industry which gives opportunities for the growth of CROs. The regulatory approval process has become increasingly stringent for clinical trials to be conducted in India. The motive is to safeguard the wellbeing of participants recruited for clinical trials. The successful alliances between pharmaceutical companies and CRO can create a culture of innovations in research and development in India.

\section{References}

1. Vennu V, Dahiya S. Awareness and Opinions of Research Professionals on India's New Drug and Clinical Trials Regulations: Protocol for a Cross-Sectional Web-Based Survey Study. JMIR research protocols. 2020 Jan 21;9(1):e14744.

2. Roberts DA, Kantarjian HM, Steensma DP. Contract research organizations in oncology clinical research: Challenges and opportunities. Cancer. 2016 May 15;122(10):1476-82.

3. Pandey A, Aggarwal A, Seth S, Maulik M, Bano R, Juneja A. Clinical Trials Registry - India: Redefining the conduct of clinical trials. Indian J Cancer 2008;45(3):7982.

4. Maysoun DM, Ramirez B, Popescu C, Reggie EM. Contract research organizations: an industry analysis. International Journal of Pharmaceutical and Healthcare Marketing 2012;6(4):336-350.

5. Young EE, Okafor $\mathrm{CN}$. Design and regulation of clinical trials; from the laboratory to the pharmacy. South American Journal of Clinical Research. 2016;3(1):1-0.

6. High Growth Forecasted for the Booming Clinical Trials Market in India. Business Wire 2009 Jan 21.

7. Yadav $P$, Jaykaran, Chaudhari M, Saxena D, Kantharia $N$. Clinical trials registered in clinical trial registry of India: A survey. Journal of Pharmacology and Pharmacotherapeutics 2011 10;2(4):289-292.

8. Tonkens R. Clinical Research Organizations Offer Wide Range of Management Opportunities for Physician Executives. Physician Exec 2005 Jan;31 (1):38-40.

9. Murray E, McAdam R. A comparative analysis of quality management standards for contract research organisations in clinical trials. Int J Health Care Qual Assur 2007;20(1):16-33.

10. Abraham J. Pharmaceuticals, the state and the global harmonisation process. Australian Health Review 2004 Nov 08;28(2):150-60.

11. Bhave A, Batolar L. Indian regulatory update AprilOctober 2018. Perspectives in Clinical Research 2019 Jan; 10(1):31-33

12. McGettigan $P$, Roderick $P$, Mahajan R, Kadam A, Pollock AM. Use of Fixed Dose Combination (FDC) Drugs in India: Central Regulatory Approval and Sales of FDCs Containing Non-Steroidal Anti-Inflammatory Drugs (NSAIDs), Metformin, or Psychotropic Drugs: e1001826. PLoS Medicine 2015 05; 12(5).

13. Sariola S, Ravindran D, Kumar A, Jeffery R. Bigpharmaceuticalisation: Clinical trials and contract research organisations in India. Social Science \& Medicine. 2015 Apr 1;131:239-46. 
14. Lustig K, Thompson M, Gul S. The evolution of the Contract Research Organisation and the future of the pharmaceutical industry. Eur. Pharm. Rev. 2013;18:60-2.

15. Varlan E, Le Paillier R. Multicriteria decision making for contract research organisation choice in the pharmaceutical industry. Journal of the Operational Research Society. 1999 Sep 1;50(9):943-8.

16. Gupta Y, Kumar B. Clinical trials and evolving regulatory science in India. Indian Journal of Pharmacology 2014 12;46(6):575-578.

17. Davis S, Sule P, Bughediwala M, Pandya V, Sinha S. Ethics committees and the changed clinical research environment in India in 2016: A perspective! Perspectives in Clinical Research 2017 Jan;8(1).

18. Fogel D. B.. Factors associated with clinical trials that fail and opportunities for improving the likelihood of success: A review. Contemporary clinical trials communications, (2018) 11, 156-164. https://doi.org/10.1016/j.conctc.2018.08.001

19. Pretorius S. Phase III trial failures: costly, but preventable. Applied Clinical Trials. 2016 Aug 1;25(8/9):36.

20. Vanessa Zainzinger, Big ambitions for India's Contract Research Firms, c\&en (Chemical and Engineering News), Volume 99, Issue 29, 2021

21. Mallath M, Chawla T. Investigators' viewpoint of clinical trials in India: Past, present and future. Perspectives in Clinical Research 2017 Jan;8(1). 